\title{
Morphological and electrophysiological field observations on electric freshwater fish of the genus Mormyrops Müller 1843 (Teleostei: Mormyridae) from West and southern Africa
}

\author{
B Kramer \\ Zoological Institute of the University of Regensburg, Universitätsstrasse 31, D-93040 Regensburg, Germany \\ e-mail: bernd.kramer@ur.de
}

\begin{abstract}
Different specimens of Mormyrops anguilloides (Linnaeus 1758) were reported to display electric organ discharge (EOD) pulses of either initially head-positive or initially negative polarity, a hypothetical sex difference that has not been substantiated to date. The morphology and EODs of $M$. anguilloides of both sexes and a sexually mature size from the Comoé and Bandama rivers, Côte d'lvoire, and the Lower and Middle Zambezi, Mozambique, displayed initially positive EODs. The morphologically similar $M$. breviceps Steindachner 1895 of both sexes and a sexually mature size from the Bandama River displayed initially head-negative EODs of biphasic waveform and long duration $(0.93-1.15 \mathrm{~ms})$ in the very-low-frequency spectral range. Mormyrops anguilloides from the Comoé and Bandama rivers were differentiated in caudal peduncle depth and in EOD waveform, pulse duration and spectral energy content. The former samples displayed a biphasic, lower-frequency EOD pulse of up to $0.42 \mathrm{~ms}$ duration, the latter a tetraphasic, high-frequency EOD of up to $0.33 \mathrm{~ms}$. It is suggested that reports of EODs of both polarities in $M$. anguilloides indicate the presence of an unrecognised species.
\end{abstract}

Keywords: allopatric speciation, amplitude spectra, communication signal, differentiation, electric organ discharges, polarity reversal, sex difference

\section{Introduction}

The Mormyridae is the largest freshwater fish family endemic to Africa, and the genus Mormyrops holds some of its largest members (1.5 $\mathrm{m}$ standard length). From various parts of West Africa and elsewhere, many Mormyrops species were described that, after critical comparison, Bigorne (1987) reduced to five. Two of these species, $M$. anguilloides (Linnaeus 1758) and M. breviceps Steindachner 1895 (Figure 1), were studied in the present paper.

The Mormyridae all emit electric organ discharges (EODs) for active electrolocation and communication (Kramer 1990, Moller 1995, Kramer 1996, Bullock et al. 2005). The waveforms of EOD pulses are species-characteristic and have been used successfully as taxonomic characters in several genera, e.g. Mormyrus (Crawford and Hopkins 1989), Pollimyrus (Kramer et al. 2003) and Hippopotamyrus (Kramer and Swartz 2010). Gosse and Szabo (1960) obtained a paradoxical result from eight $M$. anguilloides specimens (then termed $M$. deliciosus Leach 1818) from the 'upper Congo basin' (most likely from near Brazzaville, République du Congo; Mme H Szabo, pers. comm.). These fish differed in the polarity of their polyphasic EODs of otherwise similar waveform: the EODs of four specimens were initially head-positive, whereas those of the other four were initially head-negative. The authors traced the polarity difference to an anatomically mirror-symmetrical innervation pattern on either the cranial or the caudal face of the electrocytes that constitute the electric organ. The EOD polarity did not correspond to a morphologically detectable species difference, and the authors concluded that the eight fish were of the same species. The authors were unable to determine the sex of their specimens, all of which were young (95-140 $\mathrm{mm}$ standard length [SL]). This is below the sexually mature size for West African $M$. anguilloides from Mali (first maturity at $325 \mathrm{~mm} \mathrm{SL}$ ) and Côte d'Ivoire (210 mm SL; Paugy 2002).

During a field study on Mormyrops specimens in Sierra Leone, West Africa, Moller and Brown (1990) observed short tetraphasic EOD pulses of, on average, $0.471 \mathrm{~ms}$ duration that were initially head-positive and, in other specimens, polarity-reversed EOD pulses of biphasic waveform and much longer duration $(1.611 \mathrm{~ms})$. All fish appeared to be members of the same species, identified as M. curviceps Roman 1966 (i.e. M. anguilloides, following Bigorne 1987), and the two EOD types were not related to developmental stage or sex. The authors proposed either the existence of two independent EOD pulseform morphs in the same species or two cryptic sibling species. Hopkins et al. (2007, reviewing unpublished data) suggest a triphasic EOD for $M$. anguilloides specimens from Cameroon and Mali (West-Central and West Africa, respectively) that was dimorphic: the EODs of some specimens started head-positive, whereas those of others started head-negative. This difference was not related to sex or developmental stage. In a fascinating report on the hunting behaviour of free-ranging $M$. anguilloides in Lake Malawi, Arnegard and Carlson (2005) report that EOD pulse 

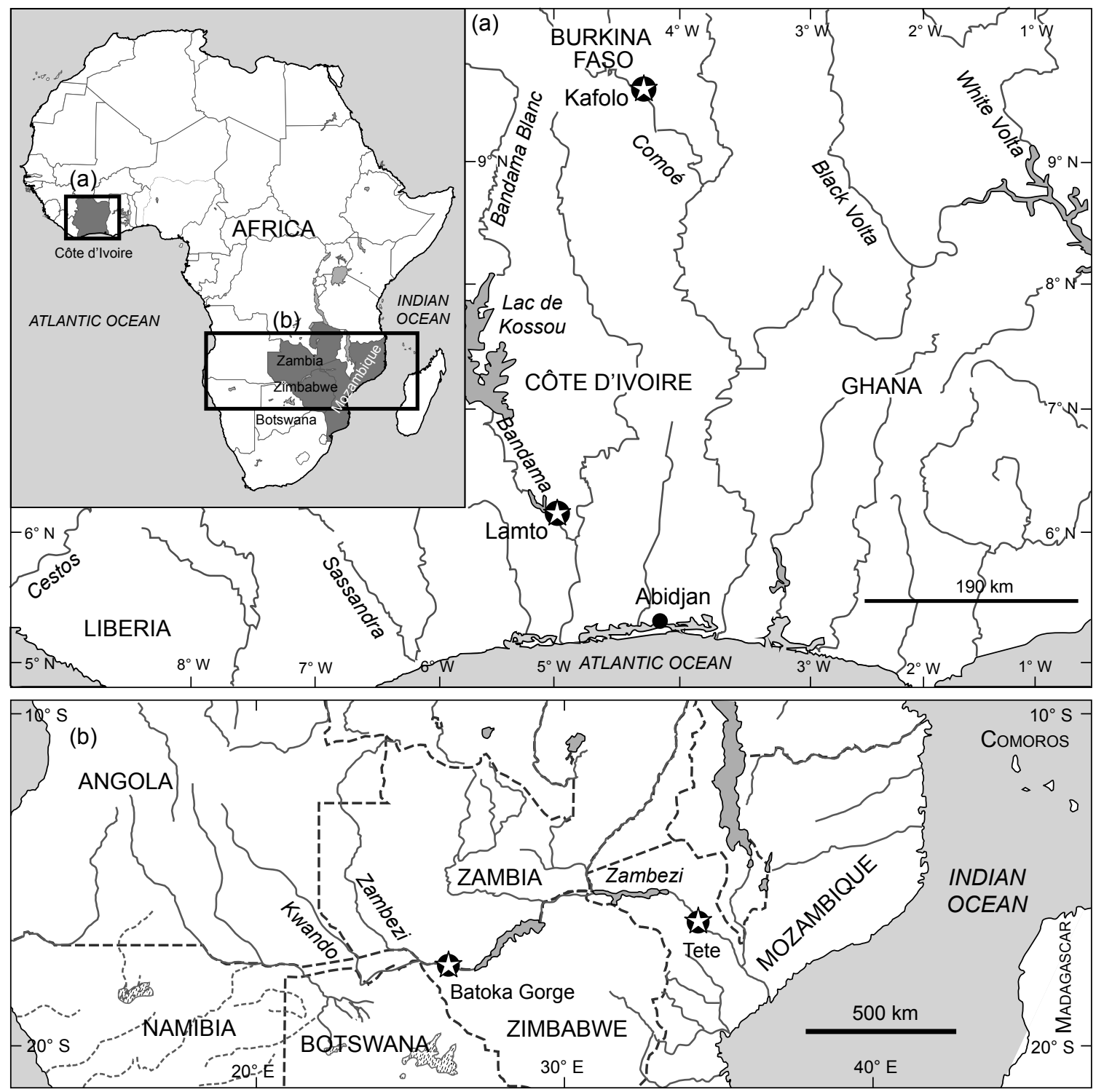

Figure 1: Location of the sample sites. (a) Map of the Bandama and Comoé rivers, Côte d'Ivoire, showing locations of sample sites at Lamto and Kafolo, respectively. (b) Map of the Zambezi River basin, showing locations of sample sites at Tete and the Batoka Gorge

duration ranged from 0.7 to $2.4 \mathrm{~ms}$, without further detail on waveform variation or polarity reversal.

These widely differing and mutually incompatible reports clearly show that the taxonomy and systematics of Mormyrops anguilloides needs revision, based on more detailed field studies, both within and between geographic populations. Part of the problem is the very extensive distribution of $M$. anguilloides as presently defined. Following the terminology of ichthyofaunal provinces in Africa, as last reviewed by Lévêque (1997, reprinted in Stiassny et al. 2007: 31), $M$. anguilloides ranges widely across the Nilo-Sudanian, the Upper and Lower Guinean, the Congo and East Coast provinces, and even an eastern part of the Zambezi province, which includes Lake Malawi. The second species studied in the present paper, M. breviceps, is restricted to part of West Africa, from the Volta River, Ghana, in the east to Guinea-Bissau in the west (approximately $0^{\circ} 15^{\prime} \mathrm{E}$ to $16^{\circ} \mathrm{W}$; estimated from the map in Bigorne 2003).

The present paper offers more quantitative EOD analyses of sexually mature, field-studied specimens, paired with detailed morphological analyses for $M$. anguilloides and $M$. breviceps specimens of a sexually mature size, sampled from two rivers in Côte d'Ivoire. For comparison, fieldstudied Zambezi specimens of the former species were also included (Figure 2). To the best of my knowledge, this paper offers the first EOD recordings of $M$. breviceps.

\section{Materials and methods}

\section{Morphology}

Seventeen anatomical measurements (Figure 3) and four counts were recorded for nine specimens from two 


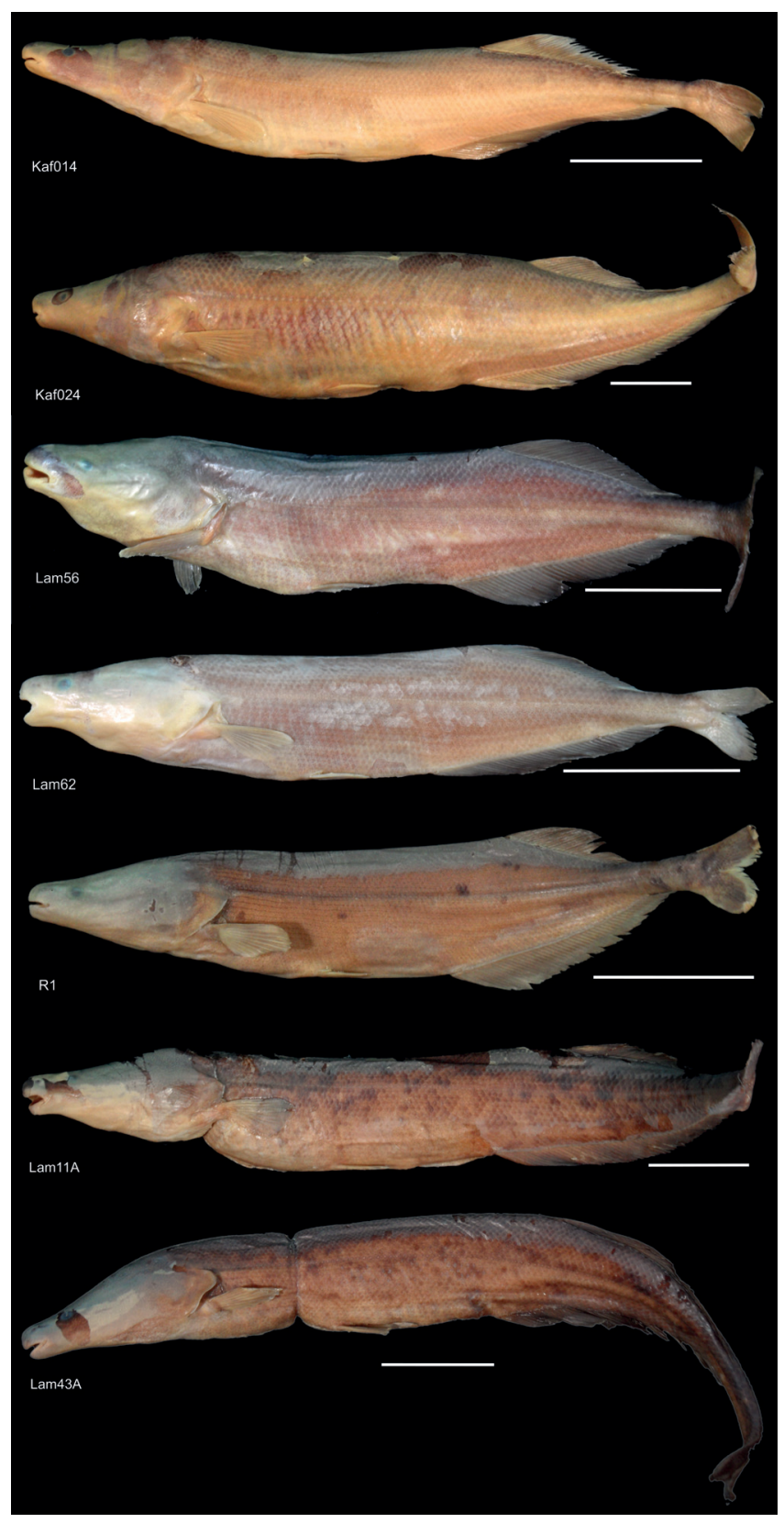

Figure 2: Photographs of Mormyrops specimens. Mormyrops anguilloides from the Comoé River: Kaf014 (SL $39.2 \mathrm{~cm}$ ), Kaf024 (SL $45.1 \mathrm{~cm}$ ); $M$. anguilloides from the Bandama River: Lam56 $(\mathrm{SL} 27.3 \mathrm{~cm})$, Lam62 (SL $19.2 \mathrm{~cm}) ; M$. anguilloides from the Lower Zambezi at Tete: R1 $(\mathrm{SL} 21.1 \mathrm{~cm}) ; M$. breviceps from the Bandama River: Lam11A (SL $39.8 \mathrm{~cm})$, Lam43A (SL $35 \mathrm{~cm})$. Scale bar $=5 \mathrm{~cm}$

origins in Côte d'Ivoire, and two origins on the Lower and Middle Zambezi in Zambia and Mozambique. The definitions of morphological characters follow mainly those of Kramer (2013a):

$\mathrm{PDL}=$ predorsal length (distance from the tip of the snout to the dorsal fin origin)

$\mathrm{PAL}=$ distance from tip of snout (= upper lip) to anal fin origin
$L D=$ dorsal fin length

$\mathrm{LA}=$ anal fin length

$\mathrm{pD}=$ distance from dorsal fin origin to end of caudal peduncle

$\mathrm{CPL}=$ length of caudal peduncle (from end of anal fin base to midbase of the caudal fin)

$\mathrm{CPD}=$ depth of caudal peduncle (shortest vertical distance across the caudal peduncle)

LSo $=$ length of snout (distance from the tip of the snout to the posterior orbital rim of the eye)

LSc $=$ length of snout (distance from the tip of the snout to the centre of the eye)

$\mathrm{HL}=$ head length (distance from the tip of the snout to the furthest bony edge of the operculum)

$\mathrm{Na}=$ distance between the pair of nares on one side (from centre to centre)

$\mathrm{OD}=$ eye diameter, defined by the orbital rims

$I O D=$ inter-orbital distance

$\mathrm{LPF}=$ length of the pectoral fins

PPF $=$ distance from the origin of the pelvic fin to the origin of the anal fin (some specimens)

$\mathrm{SL}=$ standard length (distance between the tip of the snout to the midbase of the caudal fin)

$\mathrm{BD}=$ body depth (the greatest vertical distance across the body)

$\mathrm{nD}=$ number of dorsal fin rays

$\mathrm{nA}=$ number of anal fin rays

$\mathrm{SPc}=$ number of scales around the caudal peduncle

SLS $=$ number of scales in a linear series along the lateral line row, as detailed by Skelton (2001: 67) (range of accuracy \pm 2 counts)

Measurements were all point-to-point; no projections into other planes were used.

The sex of the Ivorian specimens was recognised by histology, and the stage of egg development determined according to Takashima and Hibiya (1995). In the present Mormyrops samples, the 'kink' character of the anal fin base, which indicates the male sex was absent, in contrast to most other mormyrid species, and thus gonad histology was the only reliable way to determine their sex. The gonads were dissected, embedded in paraffin wax, and $7 \mu \mathrm{m}$ sections were stained following the Azan protocol (Mulisch and Welsch 2010; for details, see Kramer 1997a).

Abbreviations used to represent institutions and collections cited follow Leviton et al. (1985) and Fricke and Eschmeyer (2013). Specimens examined were identified using the dichotomous keys of Lévêque and Paugy (1984), Lévêque et al. (1990) and Bigorne (2003), which are considered effective for fish populations occurring in West Africa. Zambezi specimens were identified following Skelton (2001).

\section{Electric organ discharges}

Electric organ discharges were recorded in the field immediately after capture of fish, following the methods of Kramer and Swartz (2010). Measurements were taken with the fish held in a 37-litre plastic aquarium filled with water from the river from which it was collected. Conditions in the aquarium were kept constant throughout the analysis to exclude the possibility that water quality (conductivity and temperature) could affect EOD measurements.

Temperature $\left( \pm 0.1^{\circ} \mathrm{C}\right)$ and water conductivity $\left( \pm 1 \mu \mathrm{S} \mathrm{cm}{ }^{-1}\right)$ were constantly monitored using an electronic apparatus 


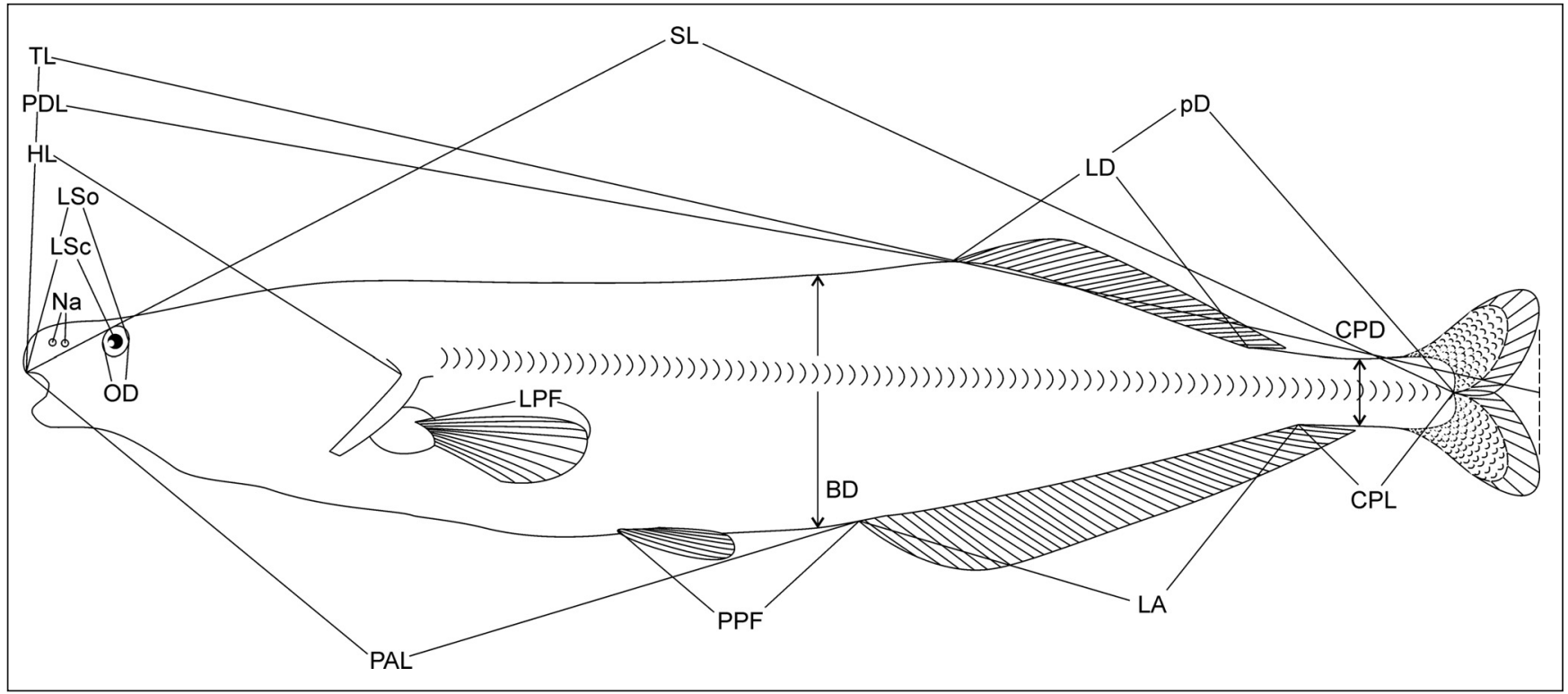

Figure 3: Morphological measurements used in the present study, indicated on a sketch of Mormyrops anguilloides. For abbreviations, see the Materials and methods

(LF318 Wissenschaftlich-Technische Werkstätten, Weilheim). Fish were placed between a pair of carbon rod electrodes that were connected to a differential amplifier with a variable gain (up to $\times 10 ; 0.2 \mathrm{~Hz}$ to $100 \mathrm{kHz}$; filter slopes, $-3 \mathrm{~dB}$ per octave; made in the electronics workshop, Biology Department, University of Regensburg, Regensburg). Amplifier output was recorded with a digital storage oscilloscope (specified to at least $20 \mathrm{MHz} / 8$ bit and either 512 , 2048 or 10000 points per sweep, depending on the model). Data were numerically transferred onto disk via a digital interface. Usually, four traces per fish were recorded. Except in the first year of the study, all field equipment was battery-operated.

Custom-designed computer programmes, using a software package for signal analysis, Famos 6.2, were used for analysis of EODs. When necessary, EOD duration was corrected to $25^{\circ} \mathrm{C}$ using a Q10 value of 1.5 (Kramer and Westby 1985) before data analysis.

The waveform variables of the tetraphasic EOD of $M$. anguilloides were defined as follows (cf. Figure 4a): $\mathrm{P} 1 \mathrm{amp}$, peak amplitude of positive P1 phase (i.e. from baseline to peak, which is equal to $|1| \mathrm{V}$ by definition); NOamp and P2amp, negative and positive peak amplitudes of pre- and post-potentials, respectively; N1amp, negative peak amplitude of N1 phase of EOD re: P1amp; NOdur, $\mathrm{P} 1$ dur and N1dur, durations of respective phases; P1N1sep, separation (or interval) between the peaks of the $\mathrm{P} 1$ and $\mathrm{N} 1$ phases; and P1area and N1area, areas under the P1 and N1 phases. Total EOD duration was defined as the sum of N0dur, P1dur and N1dur; P2dur was excluded owing to its weak amplitude and slow approach of the baseline in certain discharges, as indicated where appropriate. Durations are given in milliseconds, and amplitudes in relative volts (re: $\mathrm{P} 1$-phase amplitude $=1 \mathrm{~V}$ ). Area-undercurve measures are given in the dimension (volts $\times$ milliseconds). The start of the initial N0 phase was determined at a threshold level of $-2 \%$ of P1amp; other phases started and ended between zero-crossings.

The waveform variables of the biphasic EOD of $M$. breviceps were defined as follows (Figure 4b): the head-negative first phase, $N$, started at $-2 \%$ of its peak amplitude, Namp, which was $|1| \mathrm{V}$ by definition. This was followed by the head-positive second phase, $\mathrm{P}$, that ended at $+2 \%$ re: Namp. The other variables were Ndur, Pdur, NPsep, Narea, Parea and EODdur, defined in the same way as described for $M$. anguilloides.

A Fast Fourier transform (FFT) routine, provided by Famos, performed amplitude spectra of single EOD pulses. Analogue-to-digital (A/D) sampling rates of EODs were reduced to between 100 and $125 \mathrm{kHz}$. The number of data points for FFT analysis was $2^{17}$, obtained by extending the baseline with zeros such that a single EOD per record was centred (Davis and Hersh 1980, Bracewell 1986, Keuper 1988). Frequency resolution was $<2 \mathrm{~Hz}$. The peak power frequency (PPF; in $\mathrm{Hz}$ ) and the frequencies at $-10 \mathrm{~dB}$ and $-20 \mathrm{~dB}$ amplitudes were determined from these spectra.

Subsequent to EOD recording, fish were killed with an overdose of the anaesthetic MS222 or 2-phenoxy-ethanol. $\mathrm{SL}$ was measured with vernier callipers or, for specimens longer than $31 \mathrm{~cm}$, a ruler prior to fixing the specimen in $10 \%$ formalin for morphological studies.

\section{Material examined}

Fish were sampled at the following four stations: (1) the Comoé River at the Campement de Recherche sur les Mouches Tsétsé, Kafolo, Côte d'Ivoire $\left(9^{\circ} 36^{\prime} \mathrm{N}, 4^{\circ} 19^{\prime} \mathrm{W}\right)$, where the river forms the international border between northern Côte d'Ivoire and Burkina Faso; (2) the Bandama River, central Côte d'Ivoire, at the Station d'Écologie de Lamto $\left(6^{\circ} 11^{\prime} \mathrm{N}, 5^{\circ} 0^{\prime} \mathrm{W}\right)$; (3) the Middle Zambezi River in the Batoka Gorge just below the Victoria Falls, on the left bank

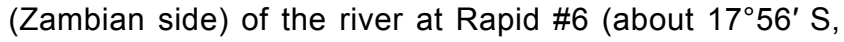


$25^{\circ} 51^{\prime} \mathrm{E}$ ), and about $800 \mathrm{~m}$ above sea level; and (4) the Lower Zambezi River at Tete, Mozambique (1609'19.3" S, $\left.33^{\circ} 36^{\prime} 01.0^{\prime \prime} \mathrm{E}\right)$, on the left bank of the river, at $119 \mathrm{~m}$ above sea level (Figure 1).

Mormyrops anguilloides (Linnaeus 1758)

ZSM 42265 (Zoologische Staatssammlung München, the Bavarian State Collection of Zoology), two specimens from the Comoé River, location Kafolo: Kaf014, SL $39.2 \mathrm{~cm}$, male, 18 April 1990, coll. B Kramer and M Postner; Kaf024, SL $45.1 \mathrm{~cm}$, female with ovary egg development stages I-II, 19 April 1990, coll. B Kramer and M Postner.

ZSM 42264, two specimens from the Bandama River, location Lamto: Lam56, SL $27.3 \mathrm{~cm}$, female, ovary stage I, 1 May 1990, coll. B Kramer and M Postner; Lam62, SL $19.2 \mathrm{~cm}$, female, ovary stage I, 1 May 1990, coll. B Kramer and M Postner.

ZSM 42267, two specimens from the Middle Zambezi, Batoka Gorge, Rapid \#6: Zam09, SL 18.1 cm, 7 December 1996, coll. FH van der Bank and B Kramer; Zam22, SL $21.2 \mathrm{~cm}$, 8 December 1996, coll. FH van der Bank and B Kramer.

ZSM 42268, one specimen from the Lower Zambezi, location: Tete: R1, SL $21.1 \mathrm{~cm}$, 3 August 2003, coll. FH van der Bank and B Kramer.

Mormyrops breviceps Steindachner 1895

ZSM 42266, two specimens from the Bandama River, location Lamto: Lam11A, SL $39.8 \mathrm{~cm}$, female, ovary weighing $11 \mathrm{~g}$, 20 April 1991, coll. B Kramer and I Kaunzinger; Lam 43A, SL $35 \mathrm{~cm}$, male, 22 April 1991, coll. B Kramer and I Kaunzinger.

\section{Ecology}

The Bandama River at Lamto is a perennial river in a region of tropical rain forest, but the water level varies considerably seasonally. Its length is about 950 km (van der Knaap 1994), and the highest water level occurs in September-October (UNESCO, Bandama River at Tiassalé; http://fr.wikipedia. org/wiki/Bandama). This is in contrast to the Comoé River at Kafolo, which is an intermittent river, $1100 \mathrm{~km}$ long (http:// www.rezoivoire.net/cotedivoire/patrimoine/105/le-reseauhydrographique-ivoirien.html\#.UTx23zdE-x0) in dry savanna and fringed by a very narrow gallery forest. The river crosses a typical Sahel zone with scattered small trees. For most of the year, in the dry season, it dries out to a series of pools (mares). Paugy's (2002) report on a similar river in Mali, the Baoulé, estimated that in the dry season the series of pools comprises only $10 \%$ of its total length, with the lower reaches being completely dry. In the Baoulé, temperature and conductivity reach $35^{\circ} \mathrm{C}$ and $120 \mu \mathrm{Sm}^{-1}$, respectively, and oxygen levels drop to 2.1-3 $\mathrm{mg} \mathrm{l}^{-1}$. Fish reproduction in the Baoulé takes place during, or shortly before, a period of intense flooding. Temperature and conductivity fall to $25^{\circ} \mathrm{C}$ and $40 \mu \mathrm{S} \mathrm{cm}^{-1}$, respectively. The period of actual flow lasts only 4-5 months (July-November). Much of Paugy's (2002) report on the Baoulé also applies to the Comoé.

\section{Results}

\section{Morphology}

Bigorne's (2003) key was consulted to identify the present sample of Mormyrops specimens from West Africa. Table 1

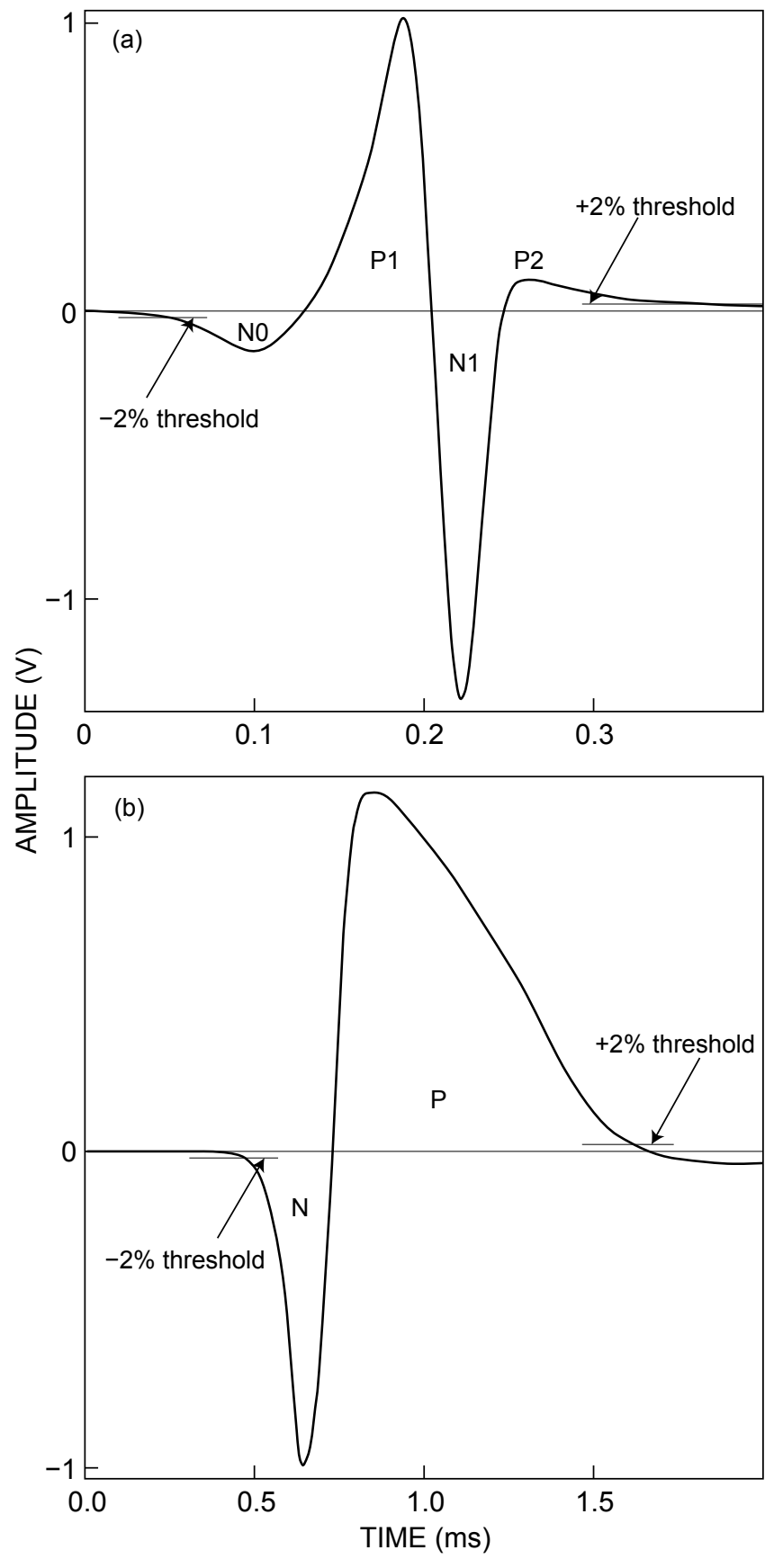

Figure 4: Definition of electric organ discharge (EOD) phases (a) in the tetraphasic EOD of Mormyrops anguilloides (specimen field code Lam62) and (b) the biphasic EOD of M. breviceps (specimen Lam43A). Both examples are for specimens from the Bandama River. The EOD amplitudes were normalised by their first main phases, which were set to equal $1 \mathrm{~V}$ from the baseline (absolute value), i.e. the $\mathrm{P} 1$ phase in $M$. anguilloides and the $\mathrm{N}$ phase in M. breviceps

shows counts and measurements for $M$. anguilloides and $M$. breviceps that can be associated with the present sample.

Four specimens, two from the Comoé River and two from the Bandama River, corresponded well with Bigorne's (2003) data for M. anguilloides in West Africa. However, in spite of the wide ranges given, specimen Kaf014 (Comoé 
River) was below the range in its caudal peduncle depth (CPD/CPL; 0.322, rather than 0.333, as the lower limit). The other Comoé specimen's CPD/CPL from the same origin (Kaf024) corresponded exactly to the lower limit.

When comparing the present samples of $M$. anguilloides from different origins, considerable differences emerged. Whereas in the Lower Zambezi specimen, R1, the number of lateral line scales (SLS) was above the West African maximum (Bigorne 2003), SLS was just within limits when following Skelton's (2001) definition (Table 1). The three Zambezi specimens' predorsal length (PDL/SL) was consistently greater than the maximum measured in the four Côte d'Ivoire specimens; the same situation pertained to the anal fin ray count (nA), which also exceeded by five rays the value that Linné (1758) reported for the (lost) type specimen. The reverse size relationship held for the length of the dorsal fin (LD/SL) and the distance 'dorsal fin origin to end of caudal peduncle' ( $\mathrm{pD} / \mathrm{SL}$ ); their maximum values in the Zambezi specimens were lower than the minimum values in the present sample of Côte d' Ivoire specimens.

The body depth (BD/SL) of the female specimen of $M$. breviceps from the Bandama River was greater than the range for this character given by Bigorne (2003), and the same specimen's number of dorsal fin rays, $\mathrm{nD}$, was lower.

Gosse and Szabo (1960) measured 11 morphological characters in each of their eight Mormyrops deliciosus (i.e. M. anguilloides) specimens. They concluded that the morphology of the two groups of specimens of different
EOD waveform was so similar that a species difference was unlikely, but suggested the possibility of a sex difference. Gosse and Szabo also highlighted the CPD/CPL data to draw attention to the somewhat higher values in specimens with an initially negative EOD. A statistical significance test between the two groups was, however, not made.

The group difference in Gosse and Szabo's (1960) CPD/CPL data proved significant in both an unpaired $t$-test $\left(t_{6}=-3.098, P=0.0212\right)$ and a Mann-Whitney $U$-test $\left(U_{1}=0.5, U_{2}=15.5, Z=-2.191, N_{1}=N_{2}=4, P=0.0284\right)$. None of the other morphological characters differed significantly between the two groups.

\section{Electric organ discharges}

The $M$. anguilloides samples all displayed basically similar EOD waveforms, with a head-positive main phase (P1) followed by a head-negative second main phase (N1) (Figure 5). In addition, all had a weak head-negative pre-potential (N0) and a weak head-positive post-potential (P2). However, in the Comoé specimens, they were so weak that they were difficult to discern at normal amplification. The amplitude of the $\mathrm{N} 1$ phase varied among origins; the highest absolute values (re: P1 phase $=|1| \mathrm{V}$ ) were observed in the Zambezi sample (N1amp $=1.65 \mathrm{~V})$, intermediate values in the Comoé sample $(\mathrm{N} 1 \mathrm{amp}=1.5 \mathrm{~V})$, and lowest values in the Bandama sample (N1amp $\leq$ 1.37 V; Table 2). No polarity-reversed waveforms were seen, including in the specimens from the Comoé River

Table 1: Morphological measurements for samples of Mormyrops species from Côte d'Ivoire, Zambia and Mozambique. For abbreviations of morphological characters, see the Materials and methods. Characters taken from Table 15.3 in Bigorne (2003), Skelton (2001) and Linné (1758) are in bold font. Superscript letters indicate measurements or counts for which discrepancies among the present sample of fish were found

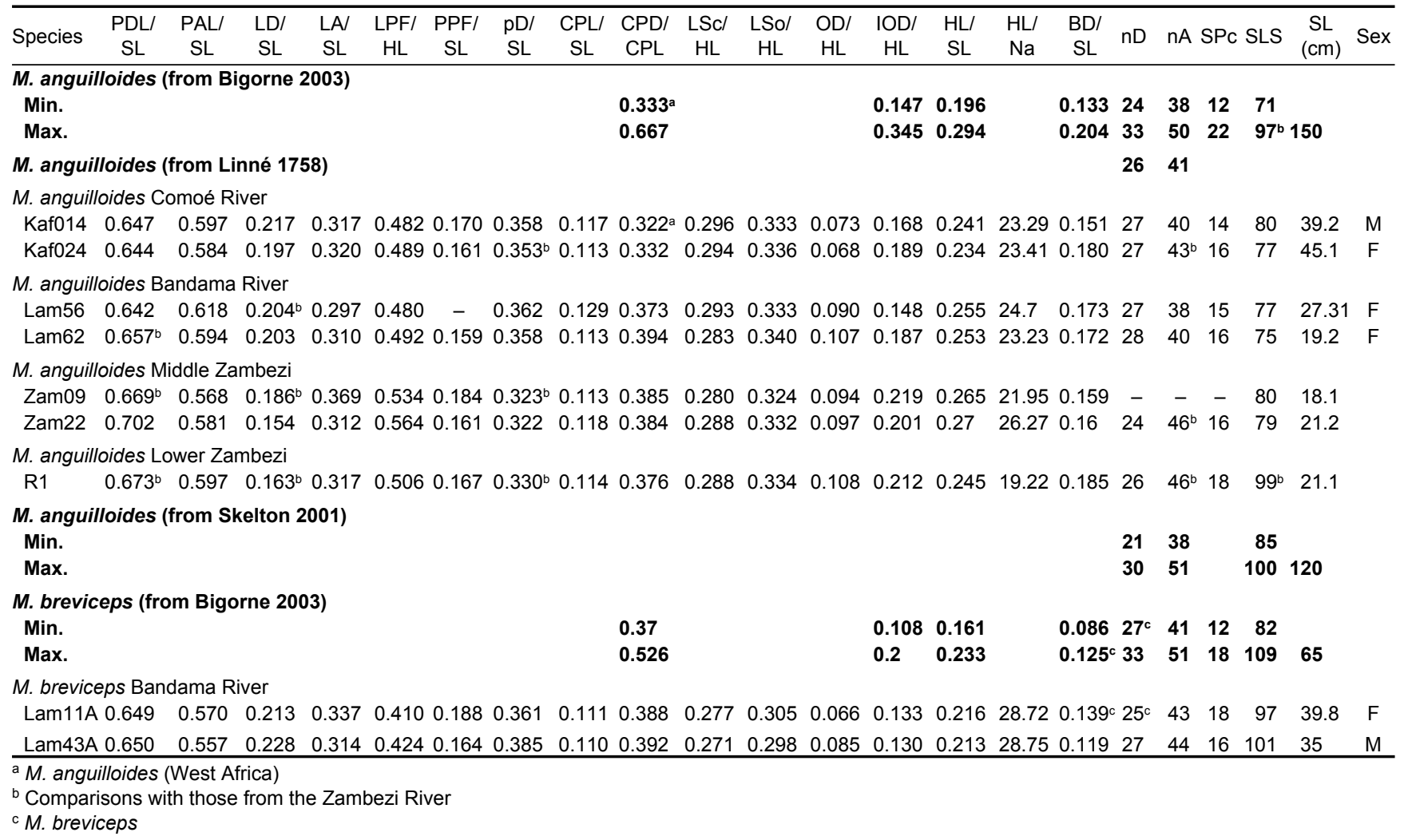


that were of both sexes. The Comoe specimens, and at least one Bandama specimen, were of a sexually mature size (over $210 \mathrm{~mm} \mathrm{SL}$ for Côte d'Ivoire; Paugy 2002), and the Comoé male's EOD lasted longer than the female's ( $0.42 \mathrm{~ms}$ vs $0.30 \mathrm{~ms}$ ). Both $\mathrm{P} 1$ and $\mathrm{N} 1$ phases of the male contributed to this effect.

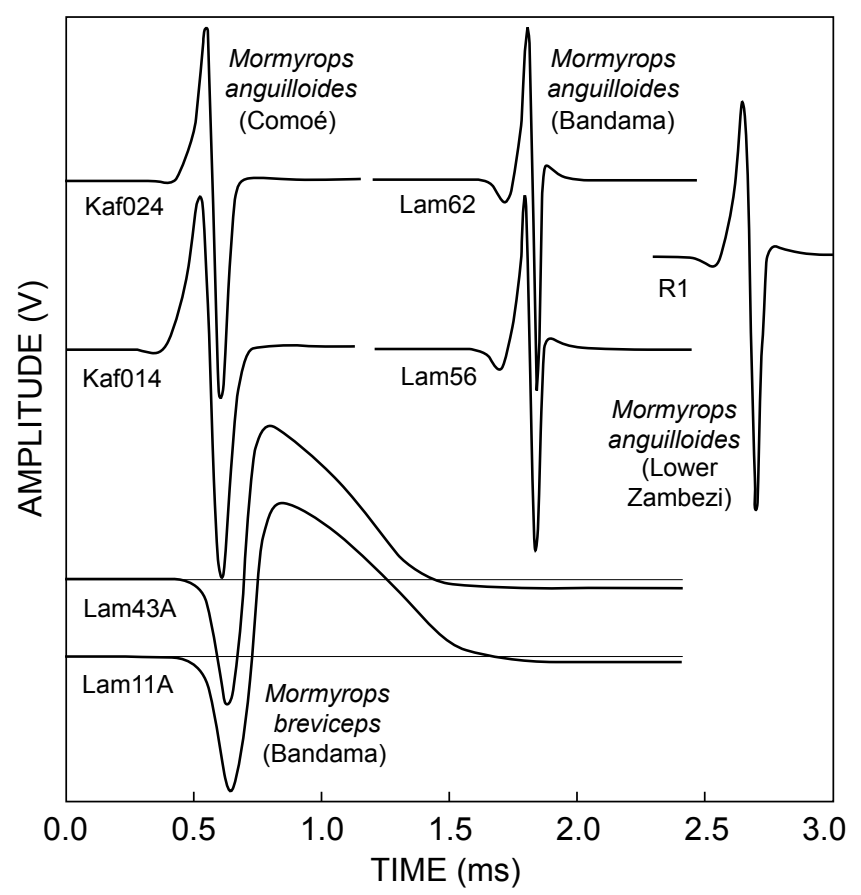

Figure 5: Field recordings of electric organ discharge (EOD) waveforms of all forms or species of Mormyrops, with field codes and the rivers they were caught in (in parentheses). Potentials above the baseline are head-positive and those below are head-negative. Mormyrops breviceps EODs are shown with the baseline superimposed. Comoé (Kafolo) and Bandama rivers (Lamto) are in Côte d'Ivoire, the Lower Zambezi recording is from Tete, Mozambique. Kaf014 and $\mathrm{Kaf024}=\mathrm{M}$. anguilloides (Comoé), Lam56 and Lam62 = M. anguilloides (Bandama), $\mathrm{R} 1=M$. anguilloides (Lower Zambezi), Lam43A and Lam11A = M. breviceps (Bandama)
The Bandama specimens were both females and, in spite of a measurable P2 phase duration that, in contrast to the Comoé EODs, contributed to the duration value of their EODs, the Bandama EODs $(0.32-0.33 \mathrm{~ms})$ did not last longer than those of the Comoé specimens. The Zambezi specimen's EOD resembled the Bandama waveform, with pre- and post-potentials $>7 \%$ re: $\mathrm{P} 1 \mathrm{amp}$, but was of slightly longer duration $(0.37 \mathrm{~ms})$. The Bandama EODs had considerably less low-frequency and much greater high-frequency content than the Comoe EODs (Figure 6). The peak power frequencies (PPFs) for the Comoé EODs were $\leq 4508 \mathrm{~Hz}$, compared to $\geq 6497 \mathrm{~Hz}$ in the Bandama EODs, whilst the Lower Zambezi specimen's EOD was intermediate $(P P F=5219 \mathrm{~Hz}$ ). Accordingly, the $-10 \mathrm{~dB}$ frequencies were much higher in the Bandama EODs $(\geq 17680 \mathrm{~Hz})$ than in the Comoé EODs $(\leq 11560 \mathrm{~Hz})$, and similarly for the $-20 \mathrm{~dB}$ frequencies.

Polarity-reversed waveforms, i.e. waveforms with an initially negative main phase, were only seen in the two $M$. breviceps specimens of opposite sex from the Bandama River; both their EODs started with a head-negative main phase followed by a large head-positive $P$ phase of long duration. There was no pre-potential. Pulse duration varied from $0.93 \mathrm{~ms}$ to $1.15 \mathrm{~ms}$, and again the longer pulse was displayed by the male. Both fish were of a sexually mature size $(\geq 35 \mathrm{~cm} \mathrm{SL}$, with maximum species size reported as $65 \mathrm{~cm} \mathrm{SL;} \mathrm{Bigorne} \mathrm{2003).} \mathrm{The} \mathrm{initial} \mathrm{N} \mathrm{phase}$ (0.21-0.25 ms) was of short duration, compared to the $\mathrm{P}$ phase of longer duration $(0.72-0.89 \mathrm{~ms})$ and higher peak amplitude $(1.14-1.22 \mathrm{~V}$ re: Namp $=|1| \mathrm{V})$. Their amplitude spectra were in the low-frequency range, with PPFs of 392 and $470 \mathrm{~Hz}$ and $-10 \mathrm{~dB}$ frequencies $\leq 3040 \mathrm{~Hz}$ on the high-frequency side. On the low-frequency side, attenuation dropped by only $2 \mathrm{~dB}$ at $1 \mathrm{~Hz}$, i.e. these EODs had a marked DC component.

\section{Discussion}

The morphological data of the four $M$. anguilloides specimens from Côte d'Ivoire, with one exception, were well within the limits given by Bigorne (2003) for the West African form of this species. Of the two specimens from the

Table 2: Electric organ discharge (EOD) waveform characters in Mormyrops specimens from the Comoé, Bandama and Lower Zambezi rivers. For abbreviations of the character names see the Materials and methods

\begin{tabular}{|c|c|c|c|c|c|c|c|c|c|c|c|c|c|}
\hline Specimen & $\begin{array}{l}\text { NOamp } \\
\text { (V) }\end{array}$ & $\begin{array}{l}\text { N1amp } \\
\text { (V) }\end{array}$ & $\begin{array}{l}\text { P2amp } \\
\text { (V) }\end{array}$ & $\begin{array}{c}\text { P1dur } \\
\text { (ms) }\end{array}$ & $\begin{array}{l}\text { N1dur } \\
\text { (ms) }\end{array}$ & $\begin{array}{l}\text { P1N1sep } \\
\text { (ms) }\end{array}$ & $\begin{array}{l}\text { P2dur } \\
(\mathrm{ms})\end{array}$ & $\begin{array}{c}\text { P1area } \\
(\mathrm{V} \times \mathrm{ms})\end{array}$ & $\begin{array}{c}\text { N1area } \\
(\mathrm{V} \times \mathrm{ms})\end{array}$ & $\begin{array}{l}\text { NOdur } \\
(\mathrm{ms})\end{array}$ & $\begin{array}{c}\text { EODdur } \\
(\mathrm{ms})\end{array}$ & $\begin{array}{c}\mathrm{SL} \\
(\mathrm{cm})\end{array}$ & Sex \\
\hline \multicolumn{14}{|c|}{ M. anguilloides Comoé River } \\
\hline Kaf014 & -0.0247 & -1.4991 & 0.0253 & 0.1848 & 0.1643 & 0.0844 & - & 0.0814 & 0.1103 & 0.0688 & 0.418 & 39.2 & M \\
\hline Kaf024 & -0.0277 & -1.4231 & 0.0264 & 0.1478 & 0.1105 & 0.0593 & - & 0.0595 & 0.0744 & 0.0426 & 0.3008 & 45.1 & $\mathrm{~F}$ \\
\hline \multicolumn{14}{|c|}{ M. anguilloides Bandama River } \\
\hline Lam56 & -0.129 & -1.315 & 0.0717 & 0.0888 & 0.0531 & 0.0416 & 0.0849 & 0.041 & 0.0387 & 0.1069 & 0.3338 & 27.3 & $\mathrm{~F}$ \\
\hline Lam62 & -0.152 & -1.3745 & 0.0949 & 0.0743 & 0.0423 & 0.0346 & 0.0945 & 0.0354 & 0.0323 & 0.105 & 0.3162 & 19.2 & $\mathrm{~F}$ \\
\hline \multicolumn{14}{|c|}{ M. anguilloides Lower Zambezi } \\
\hline $\mathrm{R} 1$ & -0.0749 & -1.6468 & 0.0727 & 0.1138 & 0.0709 & 0.0537 & 0.0857 & 0.0521 & 0.0619 & 0.0966 & 0.367 & 21.1 & \\
\hline Specimen & & $\begin{array}{l}P \\
\text { (V) }\end{array}$ & & $\begin{array}{l}\text { Pdur } \\
\text { (ms) }\end{array}$ & $\begin{array}{l}\text { Ndur } \\
\text { (ms) }\end{array}$ & $\begin{array}{c}\text { NPsep } \\
(\mathrm{ms})\end{array}$ & & $\begin{array}{c}\text { Parea } \\
(\mathrm{V} \times \mathrm{ms})\end{array}$ & $\begin{array}{c}\text { Narea } \\
(\mathrm{V} \times \mathrm{ms})\end{array}$ & & $\begin{array}{c}\text { EODdur } \\
(\mathrm{ms})\end{array}$ & $\begin{array}{c}\mathrm{SL} \\
(\mathrm{cm})\end{array}$ & Sex \\
\hline \multicolumn{14}{|c|}{ M. breviceps Bandama River } \\
\hline Lam11A & & 1.2198 & & 0.7216 & 0.2096 & 0.1637 & & 0.4987 & 0.0961 & & 0.9312 & 39.8 & $\mathrm{~F}$ \\
\hline Lam43A & & 1.1423 & & 0.8921 & 0.2546 & 0.2039 & & 0.5599 & 0.1168 & & 1.1467 & 35 & M \\
\hline
\end{tabular}



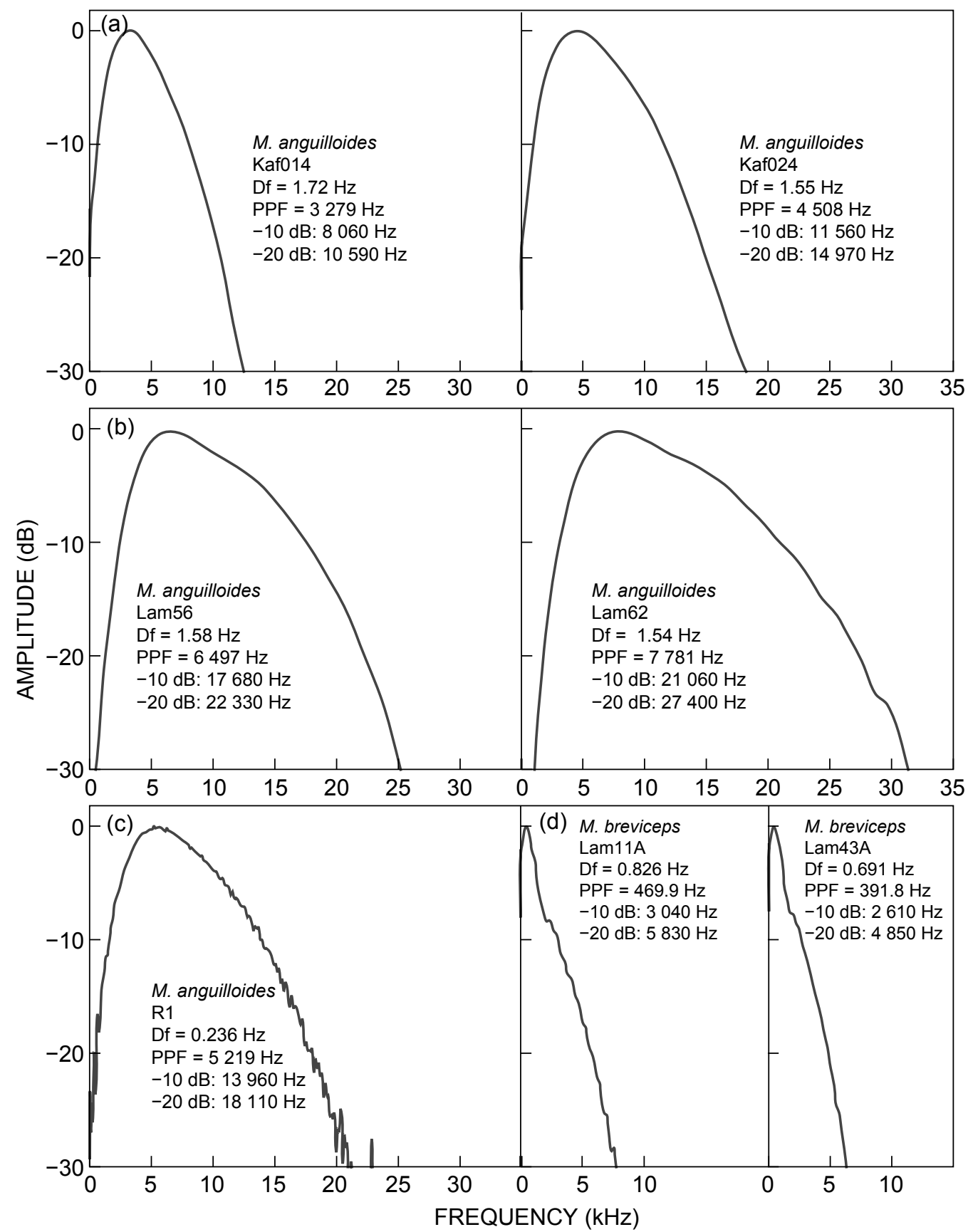

Figure 6: Amplitude spectra of single electric organ discharge (EOD) pulses of Mormyrops species. Amplitudes relative to the strongest spectral signal component $=0 \mathrm{~dB}$. The abscissae give the frequency in $\mathrm{kHz}$. (a) Two specimens of $M$. anguilloides from the Comoé River, Côte d'Ivoire, with field code numbers; (b) two specimens of $M$. anguilloides from the Bandama River, Côte d'Ivoire, with field code numbers; (c) M. anguilloides from the Lower Zambezi; (d) two M. breviceps specimens from the Bandama River, Côte d'Ivoire, with field code numbers. $\mathrm{Df}=$ Frequency resolution, $\mathrm{PPF}=$ peak power frequency; frequencies at $-10 \mathrm{~dB}$ and $-20 \mathrm{~dB}$ re: $0 \mathrm{~dB}$ on the high frequency side

Comoé River, but not those from the Bandama River, one had a caudal peduncle only as deep (CPD/CPL), and the other specimen even less deep, than the lower limit given by Bigorne (2003). Bigorne's (1987) definition of M. anguilloides includes several nominal species and one subspecies, namely $M$. deliciosus (Leach 1818), M. longiceps (Günther 1867), M. curviceps Roman 1966, and M. anguilloides voltae Roman 1966. Therefore, and because of the recognition of geographical clines rather than species differences, the ranges given for morphological characters are wide (Bigorne 1987, 2003). The two Comoé samples, with their slender caudal peduncles, are therefore surprising.

Caudal peduncle depth to length ratio is the one variable that Gosse and Szabo (1960) highlighted as potentially betraying a species difference between their eight Mormyrops samples, four of polarity- and four of 
non-polarity-reversed EODs, a hypothesis they then rejected in favour of a sex difference. They were, however, unable to confirm this since their specimens were of an immature size. As the present paper shows, the two EOD groups (inverted or not) differed significantly in their caudal peduncle depth to length ratios (see Results). The type of caudal peduncle (deep or slender) is correlated with the type of EOD polarity and the type of innervation pattern of electrocytes, as shown by Gosse and Szabo (1960). Together, these correlated observations strongly argue in favour of a species difference, not a sex difference. Caudal peduncle depth and length were identified as the most variable morphological characters among Mormyrus samples of several species across Africa, loading principal component 1 most strongly (Kramer 2013a). Mormyrus is a genus whose members also tend to be large, and in mormyrids the caudal peduncle holds the electric organ.

Polarity-inverted and non-inverted EODs in members of the same species were not seen in the present study. The two Comoé samples of opposite sex and sexually mature size displayed short, biphasic EOD pulses of 0.3-0.42 ms duration and similar waveform, with an initially positive main phase P1 (the male pulse was of the longer duration). At $<3 \%$ of the $\mathrm{P} 1$ main phase, $\mathrm{P} 1$ amplitude, a head-negative pre-potential and a head-positive post-potential were present, but very weak. This is in contrast to the EODs of the two Bandama samples and the Zambezi specimen, which had well-developed pre- and post-potentials (7-15\% of P1amp), but were otherwise of similar waveform compared to the Comoé specimens. The only polarity-reversed EODs (with an initially head-negative main phase) seen in the present specimens were those of $M$. breviceps, the two specimens of which were of opposite sex and sexually mature size. The male's and the female's EODs were of the same waveform, and again the male EOD was of longer duration (1.15 rather than $0.93 \mathrm{~ms}$ ). Mormyrops breviceps is morphologically very close to M. anguilloides (Bigorne 2003: 187). Could some of the reports of polarity-reversed EODs be due to misidentified $M$. breviceps, or forms of that species, as has happened before (Bigorne 1987)?

A species difference for the Mormyrops specimens of Gosse and Szabo (1960) should also not be ruled out when considering other mormyrid genera, several cryptic sibling species of which were discovered by EOD waveform differences. It is true that several mormyrid species exhibit a sex difference in EOD pulse duration, but not pulse polarity as hypothesised by Gosse and Szabo (1960). The most spectacular sex difference known to date was observed in field-studied, sexually mature Marcusenius altisambesi Kramer, Skelton, van der Bank and Wink 2007 with an approximately 10-fold increase in male pulse duration during the reproductive season (Kramer 1997b, Kramer et al. 2007). A marked downshift of the amplitude spectrum to low frequencies is associated with this change, putting the males at a high predation risk from certain electroreceptive catfish (Hanika and Kramer 2000). A simple inversion of a pulse waveform, such as that seen in Gosse and Szabo's (1960) fish, however, does not change the amplitude spectrum and is equivalent to a $180^{\circ}$ phase shift of its spectral components. Trained, food-rewarded Pollimyrus adspersus (Günther 1866) discriminated playbacks of synthesised versions of artificial EODs, modelled on their species' EOD, that differed only in polarity; the experimental subjects also discriminated much smaller phase shifts than $180^{\circ}$ (Paintner and Kramer 2003). This sensory acuity clearly aids in individual recognition of conspecifics by EOD waveform, which was shown in trained, food-rewarded $P$. adspersus and Gnathonemus petersii (Günther 1862) (Graff and Kramer 1992).

Cryptic sibling species were first detected by EOD waveform differences that, when investigated, were substantiated by morphological and/or genetic differentiation in the pair Mormyrus rume Valenciennes 1846/ M. subundulatus Roberts 1989 (Crawford and Hopkins 1989, Roberts 1989, Kramer 2013a), the genus Campylomormyrus Bleeker 1874 (Feulner et al. 2006), the Marcusenius macrolepidotus (Peters 1852) complex (Kramer et al. 2007, Kramer and Wink 2013), the Marcusenius species of Côte d'Ivoire (Kramer 2013b), the Pollimyrus castelnaui (Boulenger 1911) complex (Kramer et al. 2003, Kramer et al. in press), the Hippopotamyrus ansorgii (Boulenger 1905) complex (Kramer et al. 2004, Kramer and Swartz 2010), the Petrocephalus catostoma (Günther 1866) complex (Kramer and van der Bank 2000, Kramer et al. 2012), and the pair Cyphomyrus discorhynchus (Peters 1852) and C. angolensis (Pellegrin 1936) (Kramer and van der Bank 2011). Similar observations, with some overlap of EOD characteristics, were made in the sibling species pair Ivindomyrus opdenboschi Taverne et Géry 1975 and I. marchei Sauvage 1879 (Lavoué et al. 2008a), and a rich EOD waveform variation was revealed in the genus Paramormyrops Taverne, Thys van den Audenaerde and Heymer 1977 (Sullivan et al. 2004).

Radically different EOD waveform shapes among species within a genus have been observed previously, for example, in Mormyrus (Kramer 2013a), Hippopotamyrus (Kramer and Swartz 2010), and Pollimyrus (Kramer et al. 2003). These are in contrast to mormyrid genera such as Marcusenius or Petrocephalus, whose members form a family of basically similar EOD waveforms that are only moderately varied among species (Kramer et al. 2007, Lavoué et al. 2008b, Kramer et al. 2012). Hence, a distant relationship between two mormyrid species cannot automatically be inferred from dissimilar EOD waveforms. Radical differences in the EODs among closely related species are, therefore, not unheard of amongst mormyrids. However, polarity inversion in the members of one and the same species, as suggested for $M$. anguilloides, is unproven to date. On the basis of all the evidence available, it is concluded that the reports of both polarity-inverted and non-inverted EOD waveforms in $M$. anguilloides most probably indicate the presence of an unrecognised species.

In addition to caudal peduncle depth, the Comoé and Bandama specimens of $M$. anguilloides showed substantial differentiation in EOD waveform and amplitude spectra. The EODs of the former specimens were essentially biphasic, relatively low-frequency pulses (with only weak pre- and post-potentials) compared to the latter, which were clearly tetraphasic, high-frequency pulses. The specimens from the two rivers also seemed to differ in N1 phase amplitudes, N1amp, which were higher in the Comoé 
specimens. This calls for clarification of their systematic relationship in future studies.

The Comoé River specimens at Kafolo live in a much harsher dry savanna environment than those of the Bandama River at Lamto in their lush tropical rainforest environment. In their intermittent river habitat, the Comoé specimens undergo a seasonal, drastic reduction of habitat volume, as well as heat and oxygen stress, compared to those in the perennial Bandama River. This difference certainly has consequences for life history and reproduction, as discussed by Paugy (2002) for the Baoulé River, which is of similar ecology, and may be connected to the differentiation observed.

The type locality of Mormyrops breviceps is Liberia ('aus dem St Paul-Flusse'; Gosse 1984). Linné (1758: 327) gives 'Habitat in Nilo' (lives in the Nile River) as the type locality for $M$. anguilloides, the type specimen of which has been lost (Gosse 1984). The differentiation observed among the present Côte d'Ivoire and Zambezi M. anguilloides specimens (Tables 1 and 2) points to the existence of undiscovered species differences across Africa that have yet to be substantiated by the critical comparison of local populations with the type material. Therefore, a neotype for $M$. anguilloides from a local population of Nile specimens is needed, chosen from a location that would have been accessible to Linné or his fish provider, unless the exact type locality can be ascertained from historical records. Only when the definition is narrowed down to characterise the type population, or one that takes its place, which is not so wide that it embraces specimens from almost the whole of Africa, will it become possible to construct the phylogeography of local populations across Africa.

Acknowledgements - Many thanks go to Prof. R Vuattoux, Station d'écologie de Lamto, and Prof. M Mühlenberg, University of Würzburg, for support and hospitality in Côte d'Ivoire, and to the governments of Côte d'Ivoire, Zambia and Mozambique for granting collecting permissions. I am grateful to Mme Helge Szabo for sharing the likely sampling region of $\mathrm{T}$ Szabo when working with J-P Gosse in Brazzaville before 1960. Professor $\mathrm{H}$ van der Bank, University of Johannesburg, is thanked for field support, $\mathrm{Dr} U$ Schliewen and D Neumann, Zoologische Staatssammlung München, for institutional collection support, Prof. P Moller, Hunter College, New York, for a joint field trip to Côte d'lvoire together with M Postner. A second trip was assisted by I Kaunzinger. I am grateful also to the Regensburg morphology team: B Otto, E Fröhlich, S Förster, B Blaul, S Füssel, T Gierl and $P$ Machnik. This research was supported by the Deutsche Forschungsgemeinschaft (grant KR 446/12-2 and previous grants).

\section{References}

Arnegard ME, Carlson BA. 2005. Electric organ discharge patterns during group hunting by a mormyrid fish. Proceedings of the Royal Society of London B 272: 1305-1314.

Bigorne R. 1987. Le genre Mormyrops (Pisces, Mormyridae) en Afrique de l'ouest. Revue d'Hydrobiologie Tropicale 20: 145-164.

Bigorne R. 2003. Mormyridae. In: Paugy D, Lévêque C, Teugels GG (eds), Poissons d'eaux douces et saumâtres de l'Afrique de l'Ouest (The fresh and brackish water fishes of West Africa), vol. 1. Paris: IRD Éditions. pp 155-222.

Bracewell RN. 1986. The Fourier transform and its applications. New York: McGraw-Hill.
Bullock TH, Hopkins CD, Popper AN, Fay RR (eds). 2005. Electroreception. New York: Springer.

Crawford JD, Hopkins CD. 1989. Detection of a previously unrecognized mormyrid fish (Mormyrus subundulatus) by electric discharge characters. Cybium 13: 319-326.

Davis PJ, Hersh R. 1980. The mathematical experience. Boston: Birkhäuser.

Feulner PGD, Kirschbaum F, Schugardt C, Ketmaier V, Tiedemann R. 2006. Electrophysiological and molecular genetic evidence for sympatrically occurring cryptic species in African weakly electric fishes (Teleostei: Mormyridae: Campylomormyrus). Molecular Phylogenetics and Evolution 39: 198-208.

Fricke R, Eschmeyer WN. 2013. A guide to fish collections in the Catalog of Fishes database. Available at http://research. calacademy.org/redirect?url=http://researcharchive.calacademy. org/research/lchthyology/catalog/fishcatmain.asp [accessed 4 January 2013].

Gosse J-P. 1984. Mormyriformes. In: Daget J, Gosse J-P, Thys van den Audenaerde DFE (eds), Check-list of the freshwater fishes of Africa. Bondy: ORSTOM; Tervuren: MRAC. pp 63-124.

Gosse J-P, Szabo T. 1960. Variation morphologique et fonctionnelle de l'organe électrique dans une même espèce de Mormyrides (Mormyrops deliciosus Leach). Comptes Rendus de l'Académie des Sciences 251: 2791-2793.

Graff C, Kramer B. 1992. Trained weakly-electric fishes Pollimyrus isidori and Gnathonemus petersii (Mormyridae, Teleostei) discriminate between waveforms of electric pulse discharges. Ethology 90: 279-292.

Hanika S, Kramer B. 2000. Electrosensory prey detection in the African sharptooth catfish, Clarias gariepinus (Clariidae), of a weakly electric mormyrid fish, the bulldog (Marcusenius macrolepidotus). Behavioral Ecology and Sociobiology 48: 218-228.

Hopkins CD, Lavoué S, Sullivan JP. 2007. Mormyridae. In: Stiassny MLJ, Teugels GG, Hopkins CD (eds), Poissons d'eaux douces et saumâtres de basse Guinée, ouest de l'Afrique centrale (The fresh and brackish water fishes of Lower Guinea, West-Central Africa), vol. 1. Paris: IRD Éditions. pp 220-334.

Keuper A. 1988. FFT in der praxis. Grundlagen und hinweise zur anwendung der Fast-Fourier-Transformation. Elektronik Journal 20: $104-110$.

Kramer B. 1990. Electrocommunication in teleost fishes: behavior and experiments. Berlin: Springer-Verlag.

Kramer B. 1996. Electroreception and communication in fishes. Stuttgart: Gustav Fischer Verlag.

Kramer B. 1997a. A field study of African elephantfish (Mormyridae, Teleostei): electric organ discharges in Marcusenius macrolepidotus (Peters, 1852) and Petrocephalus catostoma (Günther, 1866) as related to sex. Journal of African Zoology 111: 313-341.

Kramer B. 1997b. Electric organ discharges and their relation to sex in mormyrid fishes. Naturwissenschaften 84: 119-121.

Kramer B. 2013a. A morphological study on species of African Mormyrus (Teleostei: Mormyridae) and their electric organ discharges. African Journal of Aquatic Science 38: 1-19.

Kramer B. 2013b. Differentiation in morphology and electrical signalling in four species of para- and sympatric Marcusenius (Teleostei: Mormyridae) from Côte d'Ivoire, West Africa. Marine and Freshwater Behaviour and Physiology 46: 105-133.

Kramer B, Bills R, Skelton P, Wink M. 2012. A critical revision of the churchill snoutfish, genus Petrocephalus Marcusen, 1854 (Actinopterygii: Teleostei: Mormyridae), from southern and eastern Africa, with the recognition of Petrocephalus tanensis, and the description of five new species. Journal of Natural History 46: 2179-2258.

Kramer B, Skelton P, van der Bank H, Wink M. 2007. Allopatric differentiation in the Marcusenius macrolepidotus species complex in southern and eastern Africa: the resurrection of $M$. pongolensis and $M$. angolensis, and the description of two 
new species (Mormyridae, Teleostei). Journal of Natural History 41: $647-708$

Kramer B, Swartz ER. 2010. A new species of slender stonebasher within the Hippopotamyrus ansorgii complex from the Cunene River in southern Africa (Teleostei: Mormyriformes). Journal of Natural History 44: 2213-2242.

Kramer B, van der Bank FH. 2000. The southern churchill, Petrocephalus wesselsi, a new species of mormyrid from South Africa defined by electric organ discharges, genetics, and morphology. Environmental Biology of Fishes 59: 393-413.

Kramer B, van der Bank FH. 2011. The Victoria Falls, a species boundary for the Zambezi parrotfish, Cyphomyrus discorhynchus (Peters, 1852), and the resurrection of Cyphomyrus cubangoensis (Pellegrin, 1936) (Mormyridae: Teleostei). Journal of Natural History 45: 2669-2699.

Kramer B, van der Bank H, Flint N, Sauer-Gürth H, Wink M. 2003. Evidence for parapatric speciation in the mormyrid fish, Pollimyrus castelnaui (Boulenger, 1911) from the OkavangoUpper Zambezi river systems: P. marianne sp. nov., defined by electric organ discharges, morphology and genetics. Environmental Biology of Fishes 77: 47-70.

Kramer B, van der Bank FH, Wink M. 2004. The Hippopotamyrus ansorgii species complex in the Upper Zambezi River system, with a description of a new species, $H$. szaboi (Mormyridae). Zoologica Scripta 33: 1-18.

Kramer B, van der Bank FH, Wink M. In press. Marked differentiation in a new species of dwarf stonebasher, Pollimyrus cuandoensis sp. nov. (Mormyridae, Teleostei), from a contact zone with two sibling species of the Okavango and Zambezi rivers. Journal of Natural History.

Kramer B, Westby GWM. 1985. No sex difference in the waveform of the pulse type electric fish Gnathonemus petersii (Mormyridae). Experientia 41: 1530-1531.

Kramer B, Wink M. 2013. East-west differentiation in the Marcusenius macrolepidotus species complex in southern Africa: the description of a new species for the Cunene River, Namibia (Mormyridae, Teleostei). Journal of Natural History. Doi: 10.1080/00222933.2013.798699.

Lavoué S, Arnegard ME, Sullivan JP, Hopkins CD. 2008b. Petrocephalus of Ozdala offer insights into evolutionary patterns of signal diversification in the Mormyridae, a family of weakly electrogenic fishes from Africa. Journal of Physiology - Paris 102: 322-339.

Lavoué S, Sullivan JP, Arnegard ME, Hopkins CD. 2008a. Differentiation of morphology, genetics and electric signals in a region of sympatry between sister species of African electric fish (Mormyridae). Journal of Evolutionary Biology 21: 1030-1045.

Lévêque C. 1997. Biodiversity dynamics and conservation: the freshwater fish of tropical Africa. Cambridge: Cambridge University Press.
Lévêque C, Paugy D. 1984. Guide des poissons d'eau douce de la zone du programme de lutte contre l'onchocercose en Afrique de l'Ouest. Paris: Convention ORSTOM-OMS.

Lévêque C, Paugy D, Teugels GG (eds). 1990. Faune des poissons d'eaux douces et saumâtres de l'Afrique de l'Ouest. Tervuren: Musée Royal de l'Afrique Centrale; Paris: Éditions de I'ORSTOM.

Leviton AE, Gibbs RH, Heal E, Dawson CE. 1985. Standards in herpetology and ichthyology: part I. Standard symbolic codes for institutional resource collections in herpetology and ichthyology. Copeia 1985: 802-832.

Linné C von. 1758. Systema naturae: per regna tria naturae, secundum classes, ordines, genera, species, cum characteribus, differentiis, synonymis, locis, Tomus I. Editio decima, reformata. Holmiae: Salvius.

Moller P. 1995. Electric fishes: history and behaviour. London: Chapman and Hall.

Moller P, Brown B. 1990. Meristic characters and electric organ discharge of Mormyrops curviceps Roman (Teleostei: Mormyridae) from the Moa River, Sierra Leone, West Africa. Copeia 1990: 1031-1040.

Mulisch M, Welsch U (eds). 2010. Romeis mikroskopische Technik. München: Spektrum Akademischer Verlag.

Paintner S, Kramer B. 2003. Electrosensory basis for individual recognition in a weakly electric mormyrid fish, Pollimyrus adspersus (Günther, 1866). Behavioral Ecology and Sociobiology 55: 197-208.

Paugy D. 2002. Reproductive strategies of fishes in a tropical temporary stream of the Upper Senegal basin: Baoulé River in Mali. Aquatic Living Resources 15: 25-33.

Roberts TR. 1989. Mormyrus subundulatus, a new species of mormyrid fish with a tubular snout from West Africa. Cybium 13: $51-54$.

Skelton P. 2001. A complete guide to the freshwater fishes of southern Africa. Cape Town: Struik.

Stiassny MLJ, Teugels GG, Hopkins CD (eds). 2007. Poissons d'eaux douces et saumâtres de basse Guinée, ouest de l'Afrique centrale (The fresh and brackish water fishes of Lower Guinea, West-Central Africa), vol. 1. Paris: IRD Éditions.

Sullivan JP, Lavoué S, Arnegard ME, Hopkins CD. 2004. AFLPs resolve phylogeny and reveal mitochondrial introgression within a species flock of African electric fish (Mormyroidea: Teleostei). Evolution 58: 825-841.

Takashima F, Hibiya T (eds). 1995. An atlas of fish histology: normal and pathological features. Stuttgart: Gustav Fischer Verlag.

van der Knaap M. 1994. Status of fish stocks and fisheries of thirteen medium-sized African reservoirs. CIFA Technical Paper no. 26. Rome: Food and Agriculture Organization of the United Nations. 